\title{
Total abdominal debranching hybrid thoracoabdominal aortic aneurysm repair versus chimneys and snorkels
}

Akiko Tanaka, MD, PhD, Gustavo S. Oderich, MD, and Anthony L. Estrera, MD

\section{ABSTRACT}

Open thoracoabdominal aortic aneurysm (TAAA) repair remains a surgical challenge. Hybrid and total endovascular repair have emerged as alternatives in treating TAAA. Total endovascular TAAA repair may be best performed with branched/ fenestrated stent grafts. However, these technologies are not yet widely available. Thus, currently total endovascular TAAA repair using the chimney/snorkel techniques is considered a viable option in many centers.

In this article, we briefly review 2 readily available techniques with off-the-shelf devices, hybrid procedure using total abdominal debranching, and total endovascular repair using chimney/snorkel procedures. The hybrid TAAA repair avoids thoracotomy but requires laparotomy and carries high morbidity and mortality (eg, operative mortality, $4 \%-26 \%$ and renal failure, $4 \%-26 \%$ ), comparable to traditional open repair. The staged hybrid approach has been proposed to minimize the invasiveness of the procedure, whereas the associated risk of interval aortic deaths is not negligible. Total endovascular repair reduces the morbidity and mortality after TAAA repair (eg, operative mortality, 3\%-20\% and renal failure, $\bigcirc \%-20 \%$ ). However, it is technically demanding and the risks of future reinterventions-and need for repetitive surveillance-is inevitable (eg, immediate type I endoleak, $7 \%-16 \%$ and 1 -year branch patency, 93\%-98\%). Currently, there are not enough data to determine which less-invasive option for open repair in patients with TAAA is superior. These alternatives should complement each other and be applied to carefully selected populations as a part of the overall toolbox in treating TAAA. (JTCVS Techniques 2021;10:28-33)

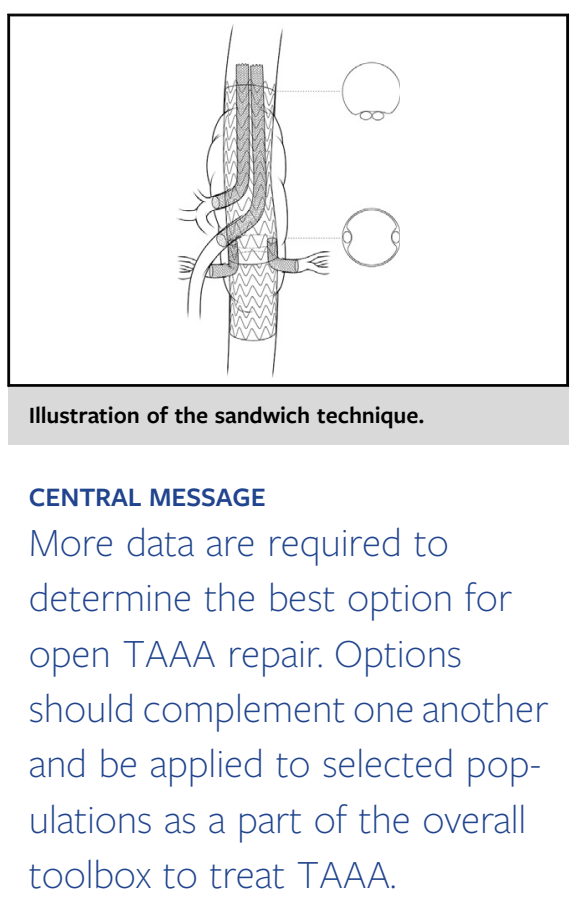

See Commentaries on pages 34 and 36.
Video clip is available online.

\section{BACKGROUND}

Open thoracoabdominal aortic aneurysm (TAAA) repair remains among the most difficult surgical challenges due to the associated vital structures, such as visceral/renal branches and segmental arteries involved

\footnotetext{
From the Department of Cardiothoracic and Vascular Surgery, McGovern Medical School at The University of Texas Health Science Center at Houston, Houston, Tex. Received for publication April 7, 2021; accepted for publication Aug 3, 2021; available ahead of print Aug 8, 2021.

Address for reprints: Anthony L. Estrera, MD, Department of Cardiothoracic and Vascular Surgery, McGovern Medical School at UTHealth, 6400 Fannin St, Suite 2850, Houston, TX 77030 (E-mail: Anthony.L.Estrera@uth.tmc.edu). 2666-2507

Copyright (c) 2021 The Author(s). Published by Elsevier Inc. on behalf of The American Association for Thoracic Surgery. This is an open access article under the CC BY-NC-ND license (http://creativecommons.org/licenses/by-nc-nd/4.0/). https://doi.org/10.1016/j.xjtc.2021.08.002
}

in the lesion. Recent reports from large-volume aortic centers demonstrate operative mortality after open TAAA repairs in young patients (younger than age 50 years) is $3 \%$ to $6 \% .^{1,2}$ However, despite the evolution in surgical techniques and perioperative care, mortality in older patients remains $8 \%$ to $17 \%$, even in experienced hands. ${ }^{1,2}$ Hybrid procedures, which combine open and endovascular techniques, to treat TAAA has been proposed ${ }^{3}$ to minimize the surgical insults and improve outcomes, especially in high-risk patients. Another alternative approach to traditional open repair is total endovascular repair with visceral parallel graft (chimney/snorkel) techniques using off-the-shelf devices. Further, physicianmodified, multibranched stent graft was introduced in $2001,{ }^{4}$ and now off-the-shelf and custom-made branched/fenestrated stent grafts to treat TAAA are being tested in clinical trials in the United States. ${ }^{5}$ There is no doubt that a total endovascular approach would benefit patients with TAAA, but the fenestrated/branched system may take years before it becomes widely available. Thus, in this review, we briefly review the 2 readily available alternative options for traditional open TAAA repair, 
hybrid repair, and total endovascular repair with chimney/ snorkels.

\section{HYBRID TAAA REPAIR}

Hybrid open/endovascular TAAA repair is performed by total abdominal debranching to reroute the visceral and renal branches followed by exclusion of the aneurysm with stent grafting (Figure 1). Quiñones-Baldrich and colleagues $^{3}$ were the first to report the technique to treat TAAA in a patient with hostile retroperitoneal space. A transperitoneal abdominal approach is commonly used to allow exposure of the entire abdominal aorta and target vessels. Retrograde extra-anatomical bypass to the celiac axis, superior mesenteric artery, and bilateral renal arteries are performed using the iliac artery as an inflow. In patients with aortic dissection causing low flow in the iliac artery or diseased iliac artery, ${ }^{6}$ the infrarenal aorta is considered for the inflow. Previous aortic grafts can be safely used as an inflow in patients with a history of abdominal aortic replacement. $^{7-9}$ The reported incidence of bowel ischemia after the hybrid TAAA repair is $3 \%$ to $18 \%$. Patency rate of the debranching bypasses exceeds $90 \%$.

Hybrid repair allows avoiding thoracotomy, extracorporeal perfusion, and supraceliac aortic clamping. The downside is that it still requires laparotomy and long operative time. Although the hybrid repair was developed as a lessinvasive approach than the traditional open TAAA repair, the 30-day mortality after hybrid techniques in many series are disappointingly high, ranging from $10 \%$ to $26 \%,{ }^{6-13}$ which may be due to the technique being applied to patients unfit or high-risk for traditional open TAAA repair. Controversial excellent outcomes were reported by Patel and colleagues in $2010,{ }^{14}$ with only 1 death in the series of 29 hybrid repairs, and Yang and colleagues in 2020, with 1 death in the series of 28 hybrid repairs. The report by Patel and colleagues also had a low morbidity rate, including spinal cord ischemia (3\%), but Yang and colleagues reported high incidence of complications, including spinal cord ischemia in $11 \%$, myocardial infarction in $21 \%$, mesenteric ischemia in $18 \%$, and respiratory failure in $32 \%$. Outcomes after hybrid TAAA repairs with more than 10 cases in the series published after 2000 are summarized in Table 1..$^{6-15}$

Staged approach with 2 to 6 weeks of recovery time after debranching procedures has been proposed to minimize the invasiveness. However, this approach carries nonnegligible risks of interval deaths, seen in $13 \%$ to $19 \%$. $^{6,13}$

Hybrid TAAA repairs with total abdominal debranching may be considered an option for patients who are not candidates for traditional open TAAA repair and whose anatomy is not suitable for endovascular procedures (eg, torturous aorta or complicated anatomy with chronic dissection). ${ }^{16}$ It should be acknowledged that morbidity and mortality after the hybrid procedures are not low.

\section{ENDOVASCULAR TAAA REPAIR WITH CHIMNEY/ PARALLEL GRAFTS}

Total endovascular repair with chimney/parallel grafts is another less-invasive alternative to traditional open TAAA repair. Chimney/parallel grafts were originally reported as
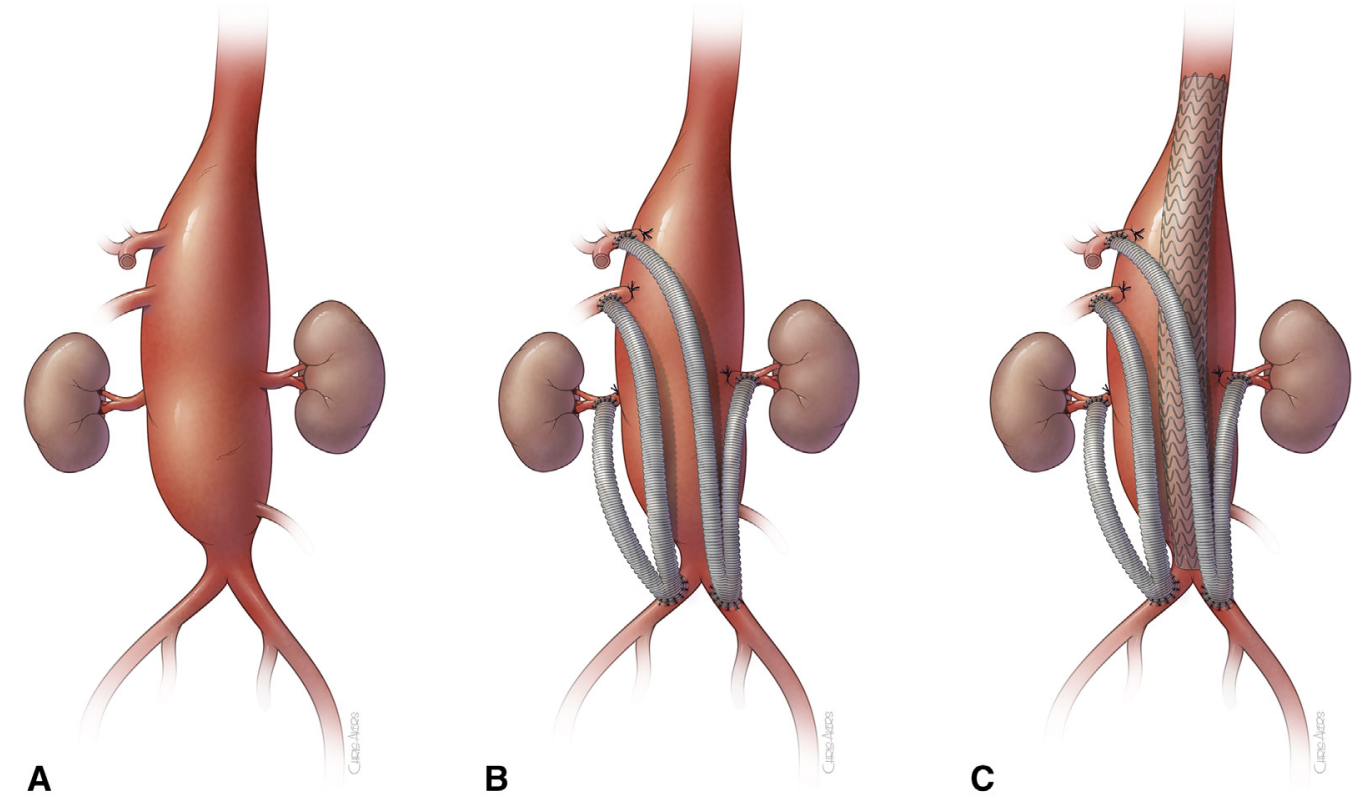

FIGURE 1. A, Illustration of extent IV thoracoabdominal aortic aneurysm. B, Debranching of the visceral and renal branches from with polyethylene terephthalate graft using Y-graft using bilateral iliac arteries for the inflow. (Note that all the branches proximal to the bypass are ligated to prevent type II endoleaks). C, Stent graft is delivered to complete the exclusion of the aneurysm. 
TABLE 1. Outcomes after hybrid thoracoabdominal aortic aneurysm repair

\begin{tabular}{|c|c|c|c|c|c|c|c|c|c|c|c|c|c|}
\hline Reference & $\mathbf{N}$ & $\begin{array}{c}\text { Mean } \\
\text { age }(y)\end{array}$ & Urgent & Dissection & $\begin{array}{c}\text { Extent } \\
\text { I }\end{array}$ & $\begin{array}{c}\text { Extent } \\
\text { II }\end{array}$ & $\begin{array}{c}\text { Extent } \\
\text { III }\end{array}$ & $\begin{array}{c}\text { Extent } \\
\text { IV }\end{array}$ & $\begin{array}{c}\text { Operative } \\
\text { death }\end{array}$ & $\begin{array}{l}\text { Permanent } \\
\text { SCI }\end{array}$ & $\begin{array}{l}\text { Respiratory } \\
\text { failure }\end{array}$ & $\begin{array}{c}\text { Bowel } \\
\text { ischemia }\end{array}$ & $\begin{array}{l}\text { Renal } \\
\text { failure }\end{array}$ \\
\hline Black et al, $2006^{7}$ & 29 & $74^{*}$ & $7(24)$ & $5(17)$ & $3(10)$ & $18(62)$ & $7(24)$ & $1(3)$ & $3(10)$ & $0(0)$ & $9(31)$ & $1(3)$ & $2(7)$ \\
\hline Chiesa et al, $2007^{8}$ & 13 & $70^{*}$ & $1(8)$ & NR & $7(54)$ & $2(15)$ & $2(15)$ & $2(15)$ & $3(17)$ & $0(0)$ & $1(8)$ & $0(0)$ & $2(15)$ \\
\hline Biasi et al, $2009^{9}$ & 18 & $73^{*}$ & $2(11)$ & $5(28)$ & $0(0)$ & $8(44)$ & $7(39)$ & $2(11)$ & $3(17)$ & $1(6)$ & $2(11)$ & $1(6)$ & $0(0)$ \\
\hline $\begin{array}{l}\text { Drinkwater } \\
\text { et al, } 2009^{6}\end{array}$ & 107 & $67^{*}$ & $22(21)$ & $28(26)$ & $11(10)$ & $45(42)$ & $32(30)$ & $1(1)$ & $16(15)$ & $9(8)$ & NR & $3(3)$ & $28(26)$ \\
\hline Patel et al, $2009^{14}$ & 23 & 77 & $7(30)$ & NR & 9 (39) & $5(22)$ & $9(39)$ & $0(0)$ & $6(26)$ & $1(4)$ & $5(21)$ & $0(0)$ & $1(4)$ \\
\hline Patel et al, $2010^{14}$ & 29 & 72 & $6(21)$ & $2(7)$ & $1(3)$ & $12(41)$ & $16(55)$ & $0(0)$ & $1(3)$ & $1(3)$ & $1(3)$ & $0(0)$ & $5(17)$ \\
\hline $\begin{array}{l}\text { Di Marco et al, } \\
2018^{11}\end{array}$ & 17 & 59 & $0(0)$ & $15(88)$ & $0(0)$ & $6(35)$ & $10(59)$ & $1(6)$ & $2(12)$ & $0(0)$ & $1(6)$ & $2(12)$ & $1(6)$ \\
\hline Kang et al, $2019^{12}$ & 24 & $64^{*}$ & $1(4)$ & $7(35)$ & $2(8)$ & $16(67)$ & $1(4)$ & $4(17)$ & $4(17)$ & $1(4)$ & NR & $0(0)$ & $2(8)$ \\
\hline Yang et al, $2020^{15}$ & 28 & 67 & $6(21)$ & $24(86)$ & NR & NR & NR & NR & $1(4)$ & $3(11)$ & $9(32)$ & $5(18)$ & $6(21)$ \\
\hline $\begin{array}{l}\text { Arnaoutakis } \\
\text { et al, } 2020^{13}\end{array}$ & 40 & 71 & $2(5)$ & $4(10)$ & $0(0)$ & $12(31)$ & $28(69)$ & $0(0 \%)$ & $5(13)$ & $1(3)$ & $11(28)$ & $4(10)$ & $8(20)$ \\
\hline
\end{tabular}

Values are presented as $\mathrm{n}(\%)$ unless otherwise noted. $S C I$, Spinal cord injury; $N R$, not reported. *Median.

a bailout procedure for unintentional coverage of the renal artery during endovascular abdominal aortic aneurysm repair, which Greenberg and colleagues ${ }^{17}$ soon adopted to treat pararenal aneurysm with short neck to create an adequate landing zone by raising the renal artery origin. Fenestrated/branched stent graft to treat juxtarenal abdominal aortic aneurysm was developed in the late 1990s and early $2000 \mathrm{~s}^{4}$ but many still use the chimney technique because of its immediate availability and less-expensive cost. In addition, off-the-shelf fenestrated/branched stent graft for TAAA is only available to limited institutions in the United States.

The clear concern with the chimney/snorkel technique is gutter leak, with type I endoleak leading to immediate and late reinterventions. Gutter leaks happen because the chimney grafts and the main body graft have different radial forces that cause space between one another. Reported incidence of type I endoleak after treating pararenal pathologies with the chimney/parallel graft technique in large-number series, such as the Performance of the Endurant Abdominal Stent Graft in the Treatment of Pararenal Pathologies by the Chimney Technique (128 patients) study, ${ }^{18}$ was $1.6 \%$, and in the Performance of the Snorkel/Chimney Endovascular Technique in the Treatment of Complex Aortic Pathologies (527 patients) Registry, ${ }^{19}$ was $14.3 \%$ in patients with grafts $\leq 20 \%$ oversizing and $1.4 \%$ for $>20 \%$ oversizing. Appropriate oversizing of the main graft is the key to prevent the gutter leak. The Performance of the Snorkel/Chimney Endovascular Technique in the Treatment of Complex Aortic Pathologies Registry data showed oversizing of ideally $30 \%$ of the Endurant (Medtronic, Minneapolis, Minn) stent graft is associated with significant lower incidence of type IA endoleaks that required reintervention for patients treated. ${ }^{19}$ Use of EndoAnchors (Medtronic), endovascular stiches with helical screws, is also suggested to decrease gutter leak. $^{20}$ Bannazadeh and colleagues $^{21}$ also reported that oversizing should be adjusted by number of chimney grafts. They recommend use of $20 \%$ oversizing for the main graft when $<2$ chimney grafts are used and $30 \%$ oversizing for 3 chimney grafts. ${ }^{21}$ However, they did not comment on the size of main graft with 4 chimney grafts, which would often be required for TAAA repair. As such, most of the literature regarding chimney grafts is for juxtarenal and pararenal abdominal aortic aneurysm-and there are scarce data available for extensive TAAA. When $>3$ chimney parallel grafts are used, there is a higher risk of gutter leak. Thus, TAAA repair with chimney technique would theoretically have higher incidence of gutter leaks compared with previous large series on pararenal/juxtarenal abdominal aortic repairs.

In the series reported by Bin Jabr and colleagues, ${ }^{22}$ the group intentionally sacrificed 31 visceral branches ( 9 celiac trunks and 22 renal arteries) in 29 patients whose cases were considered urgent with 30-day mortality of $10 \%$. Their results may justify sacrificing the celiac trunk or renal arteries in urgent circumstances. However, it is important to note that chronic renal impairment after renal artery sacrifice was seen in $57 \%$ of the patients in the series. Also, although it is rare, hepatic failure after celiac axis exclusion may be encountered $^{23}$ when collateral from the superior mesenteric artery is insufficient.

The chimney/snorkel technique may be sufficient to treat extent IV TAAA but may not be applicable to TAAAs with disease extending above the visceral branches. The sandwich technique, originally described by Lobato and colleagues, ${ }^{23}$ is intended to address the limitation of the chimney technique by extending the main graft proximally to create further proximal sealing in cases of extent I, II, and 
III TAAA, and have the inflow of the chimney grafts within the thoracic stent graft. This technique can also be combined with parallel/snorkel to minimize the number of branch grafts within the main body graft, as described by Bannazadeh and colleagues. ${ }^{21}$ The proximal-most main body stent graft holds the 2 parallel/snorkels to the celiac and superior mesenteric artery, whereas the branches to the renal arteries sit inside the proximal-most graft but outside the distal stent graft that is deployed after all the other stent grafts (Figure 2). They treated 38 suprarenal abdominal aortic aneurysms and TAAAs, reporting that reinterventions due to endoleaks were required in 5 patients $(13 \%)(1$ type IA, 1 type IB, 2 type III, and 1 gutter endoleak).

The chimney/snorkel techniques require bilateral femoral for the main body delivery and axillary/subclavian artery access for the branch access. Thus, patients with shaggy aortic arch are not ideal for the technique

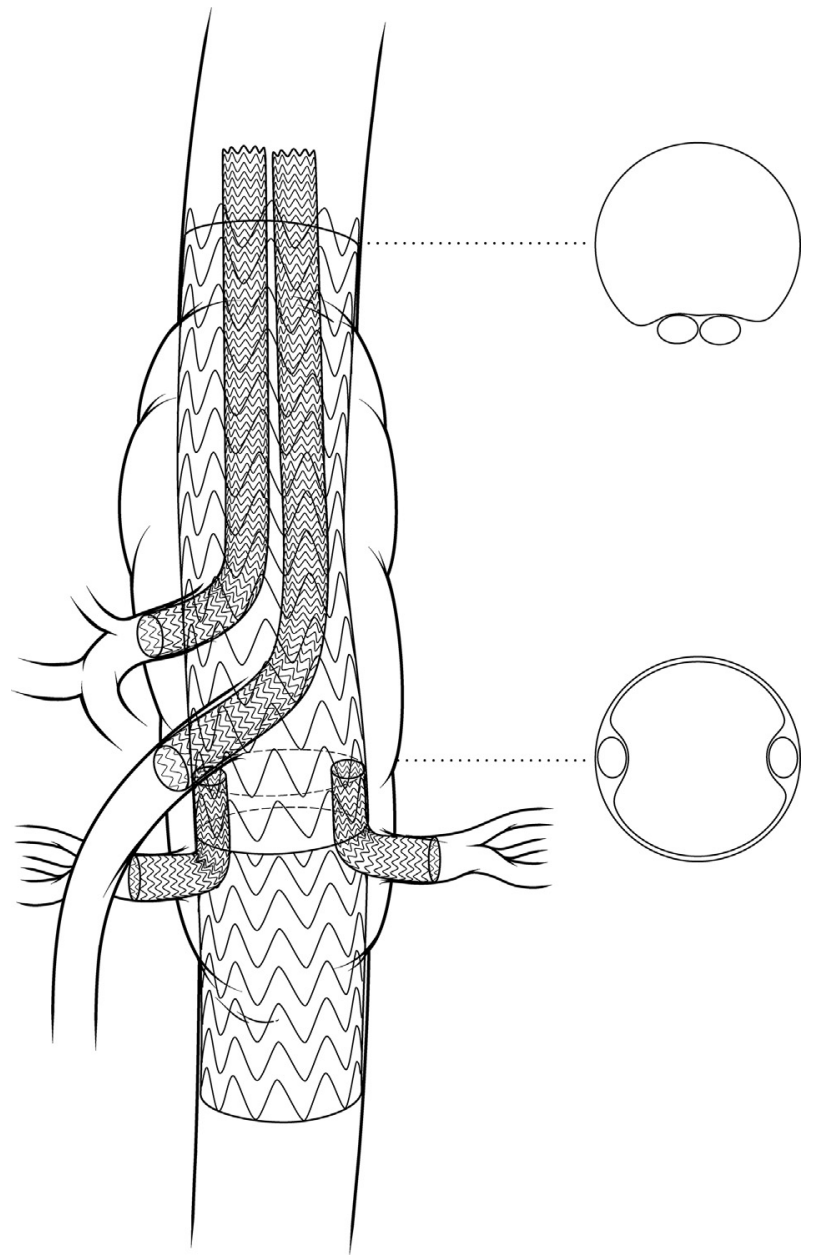

FIGURE 2. Snorkel and sandwich technique. Illustration of the sandwich technique. Note that 2 snorkel grafts are inserted into the celiac axis and superior mesenteric artery and the branch grafts to the renal arteries are "sandwiched" between the 2 main body stent grafts.

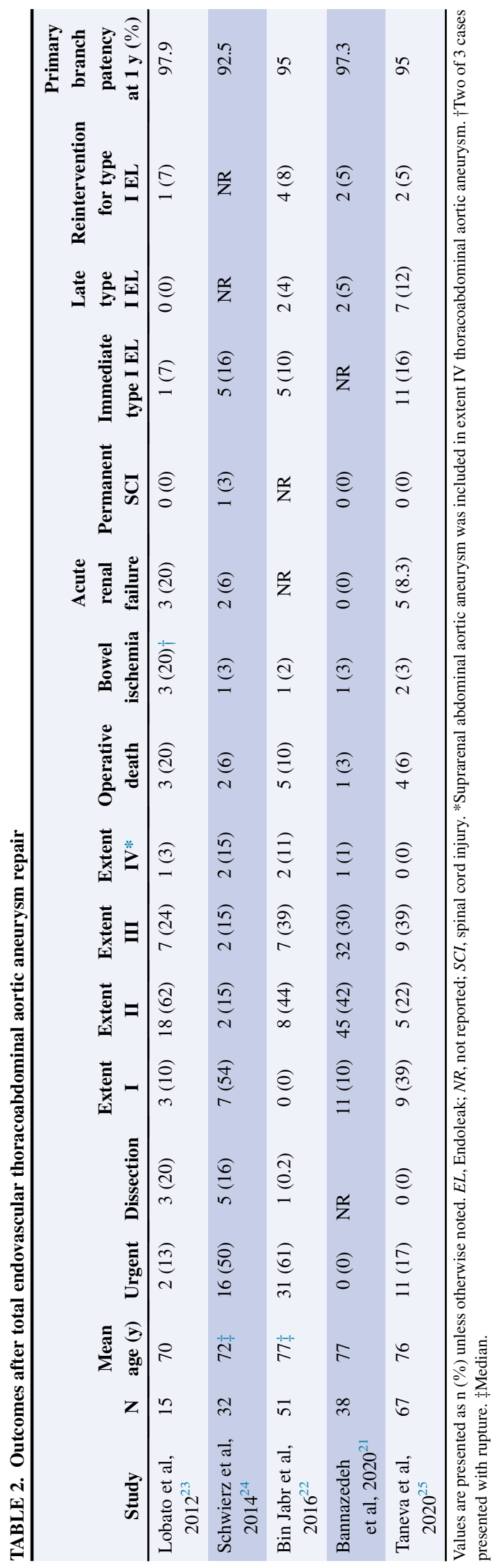

JTCVS Techniques $・$ Volume 10, Number C 
TABLE 3. Advantages and drawbacks of hybrid versus chimney/snorkel techniques

\begin{tabular}{|c|c|c|}
\hline Technique & Advantages & Drawbacks \\
\hline Hybrid repair & - Less anatomical limitations & $\begin{array}{l}\text { - Requires laparotomy } \\
\text { - High mortality and morbidity } \\
\text { - Inflow dependent } \\
\text { - Nonanatomical flow to the visceral branches }\end{array}$ \\
\hline Chimney/snorkel techniques & $\begin{array}{l}\text { - Preserved anatomical flow to the } \\
\text { visceral branches } \\
\text { - Less invasive }\end{array}$ & $\begin{array}{l}\text { - Gutter leaks, endoleaks } \\
\text { - May be difficult in dissected aneurysms and disease branches } \\
\text { - Stroke risks with shaggy aortic arch } \\
\text { - Technically demanding }\end{array}$ \\
\hline
\end{tabular}

because they are at high risk for embolic stroke. Because the size of main body graft in the paravisceral segment needs $20 \%$ to $30 \%$ oversizing to provide enough radial force to prevent the gutter leak, anatomical consideration should include the size of both the abdominal and thoracic aorta to match. This is especially true if the thoracic aorta is large and requires a large-size stent graft because the radial force provided by the sandwich between the paravisceral and thoracic extension main body may not be sufficient to prevent the leak.

Further studies are required to determine the safety and efficacy of the techniques to best treat extensive TAAAs, such as extent II and extent III. Outcomes after hybrid chimney/snorkel repairs with more than 10 cases in the series published after 2000 are summarized in Table 2.1-25 Reported operative mortality varies from $3 \%$ to $20 \%$, with low spinal cord injury rate of $0 \%$ to $3 \%$. Bowel ischemia was seen in $2 \%$ to $3 \%$ of cases (except for 3 of 15 [20\%] in 1 series, of which 2 were related to ruptured TAAA before repair $^{23}$ ). Outcomes reported in these series are excellent. However, these are from very experienced centers. More data are needed before interpreting for the real world.

\section{OUR INSTITUTIONAL PREFERENCE}

In our current practice, our mainstay to treat TAAA is open repair and total endovascular repair with fenestrated/
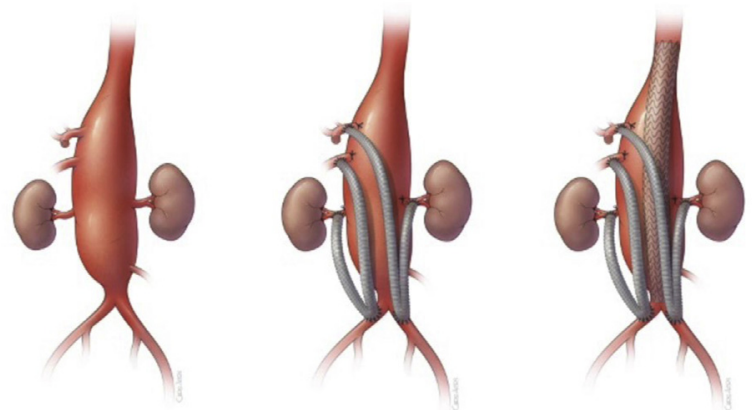

VIDEO 1. Summary of the article is discussed in the video. Video available at: https://www.jtcvs.org/article/S2666-2507(21)00550-2/fulltext. branched stent grafts or physician-modified stent grafts. Fenestrated grafts and physician-modified grafts are designed for each patient and preserves normal anatomy without risk of gutter leaks. In patients younger than age 60 years, patients with connective tissue disorder, or patients with chronic aortic dissection, we consider open repair the first choice. We have performed very few hybrid debranching repairs and snorkel/chimney techniques for those deemed unfit for either of the procedures. Snorkel/ chimney techniques have a role in emergency situations because fenestrated/branched devices need a few months of waiting time and a physician-modified graft may take 1 to 2 hours to prepare (Table 3). Hybrid procedures may benefit patients in emergency situations, such as poor lung function, who would not tolerate single-lung ventilation and for whom there is expected to be difficult access to the visceral branches with endovascular techniques (Video 1).

\section{CONCLUSIONS}

There are not enough data to determine which alternative option for open repair in patients with TAAA is superior. Alternatives should complement one another and be applied to carefully selected populations as a part of the overall toolbox to treat TAAA. Referral of these patients with complex conditions to high-volume aortic centers with multidisciplinary teams prepared for these complicated cases cannot be overemphasized, if time allows.

\section{Conflict of Interest Statement}

Dr Estrera is a consultant for W.L. Gore. Dr Oderich is a consultant for Cook Medical, W.L. Gore, and GE Healthcare. Dr Tanaka reported no conflicts of interest.

The Journal policy requires editors and reviewers to disclose conflicts of interest and to decline handling or reviewing manuscripts for which they may have a conflict of interest. The editors and reviewers of this article have no conflicts of interest.

\section{References}

1. Coselli JS, Amarasekara HS, Green SY, Price MD, Preventza O, de la Cruz KI, et al. Open repair of thoracoabdominal aortic aneurysm in patients 50 years old and younger. Ann Thorac Surg. 2017;103:1849-57. 
2. Tanaka A, Sandhu HK, Afifi RO, Miller CC III, Ray A, Hassan M, et al. Outcomes of open repairs of chronic distal aortic dissection anatomically amenable to endovascular repairs. J Thorac Cardiovasc Surg. October 1, 2019 [Epub ahead of print].

3. Quinones-Baldrich WJ, Panetta TF, Vescera CL, Kashyap VS. Repair of type IV thoracoabdominal aneurysm with a combined endovascular and surgical approach. J Vasc Surg. 1999;30:555-60.

4. Chuter TA, Gordon RL, Reilly LM, Pak LK, Messina LM. Multi-branched stent graft for type III thoracoabdominal aortic aneurysm. J Vasc Interv Radiol. 2001; 12:391-2.

5. Mirza AK, Tenorio ER, Kärkkäinen JM, Pather K, Kratzberg J, Mendes BC, et al. Outcomes of a novel upper extremity preloaded delivery system for fenestratedbranched endovascular repair of thoracoabdominal aneurysms. J Vasc Surg. 2020;72:470-9.

6. Drinkwater SL, Bockler D, Eckstein H, Cheshire NJ, Kotelis D, Wolf O, et al. The visceral hybrid repair of thoraco-abdominal aortic aneurysms-a collaborative approach. Eur J Vasc Endovasc Surg. 2009;38:578-85.

7. Black SA, Wolfe JH, Clark M, Hamady M, Cheshire NJ, Jenkins MP. Complex thoracoabdominal aortic aneurysms: endovascular exclusion with visceral revascularization. J Vasc Surg. 2006;43:1081-9.

8. Chiesa R, Tshomba Y, Melissano G, Marone EM, Bertoglio L, Setacci F, et al. Hybrid approach to thoracoabdominal aortic aneurysms in patients with prior aortic surgery. J Vasc Surg. 2007;45:1128-35.

9. Biasi L, Ali T, Loosemore T, Morgan R, Loftus I, Thompson M. Hybrid repair of complex thoracoabdominal aortic aneurysms using applied endovascular strategies combined with visceral and renal revascularization. J Thorac Cardiovasc Surg. 2009;138:1331-8.

10. Patel R, Conrad MF, Paruchuri V, Kwolek CJ, Chung TK, Cambria RP. Thoracoabdominal aneurysm repair: hybrid versus open repair. J Vasc Surg. 2009; 50:15-22.

11. Di Marco L, Murana G, Leone A, Alfonsi J, Mariani C, Cefarelli M, et al. Hybrid repair of thoracoabdominal aneurysm: an alternative strategy for preventing major complications in high risk patients. Int J Cardiol. 2018;271:31-5.

12. Kang PC, Bartek MA, Shalhub S, Nathan DP, Sweet MP. Survival and patientcentered outcome in a disease-based observational cohort study of patients with thoracoabdominal aortic aneurysm. J Vasc Surg. 2019;70:1427-35.

13. Arnaoutakis DJ, Scali ST, Beck AW, Kubilis P, Huber TS, Martin AJ, et al. Comparative outcomes of open, hybrid, and fenestrated branched endovascular repair of extent II and III thoracoabdominal aortic aneurysms. J Vasc Surg. 2020;71:1503-14.

14. Patel HJ, Upchurch GR Jr, Eliason JL, Criado E, Rectenwald J, Williams DM, et al. Hybrid debranching with endovascular repair for thoracoabdominal aneurysms: a comparison with open repair. Ann Thorac Surg. 2010;89:1475-81.
15. Yang G, Zhang M, Muzepper M, Du X, Wang W, Liu C, et al. Comparison of physician-modified fenestrated/branched stent grafts and hybrid viscera debranching plus stent graft placement for complex thoracoabdominal aortic aneurysm repair. J Endovasc Ther. 2020;27:749-56.

16. Duprey A, Ben Ahmed S, Della Schiava N, Feugier P, Rosset E, Favre JP, et al. Treatment of complex aortic aneurysms using combination of renal and visceral bypass and fenestrated/branched stent grafts. Ann Vasc Surg. 2019; 57:91-7.

17. Greenberg RK, Clair D, Srivastava S, Bhandari G, Turc A, Hampton J, et al Should patients with challenging anatomy be offered endovascular aneurysm repair? J Vasc Surg. 2003;38:990-6.

18. Donas KP, Torsello GB, Piccoli G, Pitoulias GA, Torsello GF, Bisdas T, et al. The PROTAGORAS study to evaluate the performance of the Endurant stent graft for patients with pararenal pathologic processes treated by the chimney/snorkel endovascular technique. J Vasc Surg. 2016;63:1-7.

19. Donas KP, Usai MV, Taneva GT, Criado FJ, Torsello GB, Kubilis P, et al. Impact of aortic stent graft oversizing on outcomes of the chimney endovascular technique based on a new analysis of the PERICLES registry. Vascular. 2019;27: 175-80.

20. Galinanes EL, Hernandez-Vila EA, Krajcer Z. EndoAnchors minimize endoleaks in chimney-graft endovascular repair of juxtarenal abdominal aortic aneurysms. Tex Heart Inst J. 2019;46:183-8.

21. Bannazadeh M, Beckerman WE, Korayem AH, McKinsey JF. Two-year evaluation of fenestrated and parallel branch endografts for the treatment of juxtarenal, suprarenal, and thoracoabdominal aneurysms at a single institution. J Vasc Surg. 2020;71:15-22.

22. Bin Jabr A, Lindblad B, Kristmundsson T, Dias N, Resch T, Malina M. Outcome of visceral chimney grafts after urgent endovascular repair of complex aortic lesions. J Vasc Surg. 2016;63:625-33.

23. Lobato AC, Camacho-Lobato L. A new technique to enhance endovascular thoracoabdominal aortic aneurysm therapy-the sandwich procedure. Semin Vasc Surg. 2012;25:153-60.

24. Schwierz E, Kolvenbach RR, Yoshida R, Yoshida W, Alpaslan A, Karmeli R. Experience with the sandwich technique in endovascular thoracoabdominal aortic aneurysm repair. J Vasc Surg. 2014;59:1562-9.

25. Taneva GT, Criado FJ, Torsello G, Veith F, Scali ST, Kubilis P, et al. Results of chimney endovascular aneurysm repair as used in the PERICLES registry to treat patients with suprarenal aortic pathologies. J Vasc Surg. 2020;71:1521-7.e1.

Key Words: thoracoabdominal aortic aneurysm, hybrid repair, minimally invasive, endovascular aortic repair, chimney technique, snorkel technique 